\title{
Study of Pb(II) Effect on Electrosynthesis of Lead Dioxide in More Environmentally Electrolyte of Methanesulfonic Acid
}

\author{
Bohao $Y u^{1}$, Ruidong $X u^{1,2, *}$, Yiyang $L^{1}$, Jingshi Zhang ${ }^{1}$, Ziyang Qin ${ }^{1}$ \\ ${ }^{1}$ Faculty of Metallurgical and Energy Engineering, Kunming University of Science and Technology, \\ Kunming 650093, China; \\ ${ }^{2}$ State Key Laboratory of Complex Nonferrous Metal Resources Cleaning Utilization, Kunming \\ 650093, China. \\ *E-mail: rdxupaper@aliyun.com
}

doi: $10.20964 / 2017.09 .28$

Received: 1 June 2017 / Accepted: 7 July 2017 / Published: 13 August 2017

\begin{abstract}
Lead dioxide has received much attention as an electrode material for its high resistance to corrosion, high electronic conductivity, good stability, long lifetime, and low cost. However, problems still exist concerning the selection of the electrolyte during electrodeposition, which may cause issues in energy conservation and environmental protection. The present study utilized the environmentally friendly electrolyte methanesulonic acid (MSA) and evaluated the effect of the $\mathrm{Pb}$ (II) concentration on the electrodeposition of lead dioxide in MSA using rotating disk electrode (RDE) voltammetry to determine the most suitable composition of the electrodeposition bath and to realize an environmentally and energy friendly process. We adequately characterised $\mathrm{PbO}_{2}$ synthesized on a $\mathrm{Pt}$ electrode surface, and the results showed that the $\mathrm{Pb}$ (II) concentration had a great influence on the electrodeposition of lead dioxide in MSA. By controlling the composition of the electrodeposition bath to $0.2 \mathrm{M} \mathrm{Pb}$ (II) and 0.1 M MSA, we obtained an optimal reversible process, longer electrode lifetime and more satisfactory environmental protection.
\end{abstract}

Keywords: lead dioxide; $\mathrm{Pb}(\mathrm{II})$ concentration; environmentally electrolyte; RDE

\section{FULL TEXT}

(C) 2017 The Authors. Published by ESG (www.electrochemsci.org). This article is an open access article distributed under the terms and conditions of the Creative Commons Attribution license (http://creativecommons.org/licenses/by/4.0/). 